\title{
Application of multiple trait analysis in animal breeding research
}

\author{
I.L. MAO \\ Department of Animal Breeding and Genetics \\ Swedish University of Agricultural Sciences, S-750 07 Uppsala, Sweden
}

The circumstances under which the use of multiple trait analysis is of advantage are discussed. The basic model for such analysis, as well as models and mixed model equations for six case studies, are formulated for the prediction of breeding values and the estimation of variances and covariances. The case studies revealed several patterns of equations. For each pattern, a computing strategy is suggested.

\section{Relationships between lifetime milk production, productive life, level of production and a lifetime profit function in cows}

\author{
A. ESSL \\ Institute of Animal Production, University of Bodenkultur, \\ Gregor Mendelstraße 33, A-1180 Vienna, Austria
}

Regarding the Austrian conditions a simple function for the profit per lactation of herdlife was derived. Some intersting results in connection with lifetime production criteria obtained from modell calculations were as follows :

For a given level of milk production per lactation the profit decreases progressively when herdlife gows down. consequently, the primary breeding task is here to avoid a decrease in herdlife at all events.

Further, there is a quite remarkable variation of the expected profit per lactation for a given lifetime production. Hence, pure lifetime production can not be designated as an ideal economic measurement for dairy cows as it is sometimes interpreted.

\section{Variation in lipolysis in milk from individual cows}

\section{P. SKIPENES}

Department of Animal Genetics and Breeding, Agricultural University 1432 As, NLH, Norway

The free fatty acid (FFA) content in milk from 60 cows were determined. Fresh and stored samples from both evening and morning milkings were analysed. The results can be summarized as follows :

a) There are considerable differences between cows in FFA-content of stored milk.

b) The correlations between fresh samples collected within a 24 hour interval are low, 0.16-0.22, whereas the correlations for stored samples are high, 0.69-0.74. The correlation between fresh and stored samples from the same milking is low, 0.17 .

c) Within-cow correlations between testing weeks are in average found to be 0.75 . 